\title{
Sero-prevalence of Toxoplasma gondii and associated risk factors among psychiatric outpatients attending University of Gondar Hospital, Northwest Ethiopia
}

Barnabas Achaw', Habtie Tesfa², Ayalew Jejaw Zeleke², Ligabaw Worku², Ayenew Addisu², Niguse Yigzaw ${ }^{3}$ and Yalewayker Tegegne $2^{2^{*}}$

\begin{abstract}
Background: Toxoplasmosis is caused by an obligatory intracellular coccidian protozoan organism, Toxoplasma gondii. It has a worldwide distribution, affecting one-third of the world population. Psychiatric patients have a higher risk of exposure to Toxoplasma gondii infection due to lack of good personal hygiene. The burden of toxoplasmosis among psychiatric patients in Ethiopia has not been studied extensively. Thus, the study aimed to determine the seroprevalence of Toxoplasma gondii and associated risk factors among psychiatric outpatients at the University of Gondar Comprehensive and Specialized Hospital Psychiatric clinic.

Methods: A cross-sectional study was conducted at the University of Gondar Comprehensive and Specialized Hospital from February to May 2018. Venous blood was collected from 304 study participants (152 psychiatric outpatients and 152 control groups). Anti-toxoplasma antibodies were determined using Onsite Toxo immunoglobulin $\mathrm{G}(\mathrm{lgG})$ and immunoglobulin M (IgM) Rapid Test. A Chi-square test was carried out to compare the two groups and a logistic regression analysis was conducted to check the association between variables. $P$-value less than 0.05 was taken as statistically significant.

Results: The seroprevalence rate of anti-Toxoplasma gondii lgG antibodies was 33.6, and 16.4\% in the psychiatric outpatients and the control samples, respectively. Anti-Toxoplasma gondii lgM sero-prevalence was $1.3 \%$ in the former patients and 3.9\% in the latter group. Owing cat ( $A O R=2.86295 \% \mathrm{Cl}=1.445-5.666 P=0.003)$, cleaning cat excreta $(A O R=2.96695 \% \mathrm{Cl}=1.317-2.652 P=0.007)$, and farming ( $A O R=2.05895 \% \mathrm{Cl}=1.018-4.163 P=0.045)$ were found to be significantly associated with the sero-prevalence of anti-Toxoplasma gondii IgG antibody.

Conclusions: This study highlighted that, the prevalence of anti-Toxoplasma gondii lgG antibodies was significantly higher in psychiatric outpatients than the control group $(p=0.001)$. Cat ownership, cleaning of cat excreta, and farming were found to be statistically significantly associated with the seroprevalence of anti-Toxoplasma gondii lgG antibody.
\end{abstract}

Keywords: Toxoplasmosis, Psychiatric, Ethiopia, Prevalence

\footnotetext{
* Correspondence: tyalewayker@yahoo.com

2Department of Medical Parasitology, School of Biomedical and Laboratory

Sciences, College of Medicine and Health Sciences, University of Gondar,

Gondar, Ethiopia

Full list of author information is available at the end of the article
}

(c) The Author(s). 2019 Open Access This article is distributed under the terms of the Creative Commons Attribution 4.0 International License (http://creativecommons.org/licenses/by/4.0/), which permits unrestricted use, distribution, and reproduction in any medium, provided you give appropriate credit to the original author(s) and the source, provide a link to the Creative Commons license, and indicate if changes were made. The Creative Commons Public Domain Dedication waiver (http://creativecommons.org/publicdomain/zero/1.0/) applies to the data made available in this article, unless otherwise stated. 


\section{Background}

Toxoplasmosis is a parasitic disease caused by Toxoplasma gondii. It is an intracellular protozoan parasite in the phylum Apicomplexan. It has a wide variety of intermediate hosts, including humans and other warmblood mammals [1]. Toxoplasmosis is a major public health problem, as a cause for a high socioeconomic impact including the cost of caring for sick, children with mental disability and blind [2].

In humans, primary infection is usually subclinical, in some patients however cervical lymphadenopathy or ocular disease can be present. Infections acquired during pregnancy may cause severe damage to the fetus. In immune compromised patients, reactivation of latent infection can cause life-threatening encephalitis [3]. The dopamine levels may be affected by $T$. gondii, resulting in alterations in CNS. Previous studies showed that behavior can be affected by latent Toxoplasma infection, possibly being a contributory, or even causative, factor in some psychiatric disorders, including anxiety, depression, and schizophrenia $[4,5]$.

Besides, Infection with toxoplasma is mostly sub-acute, with signs of focal neurologic which happens along with altered mental state, fever, and headache. Subcortical or cortical lesions of the brain can be present in over half of the patients with toxoplasmosis, resulting in hemiparesis, ambulatory, and difficulty of speaking and walking problems [6].

T.gondii has a complex life cycle and is an important foodborne pathogen. The major means of transmission to humans results from the ingestion or handling of undercooked or raw meat containing tissue cysts. On the other hand, the human can get the infection due to direct contact with cats or from the consumption of water or food contaminated by oocysts excreted in the feces of infected cats [7].

IgM and IgG antibodies detection in the patient's serum is the commonly used method of toxoplasmosis diagnosis. Within a few days to one week of T. gondii infection, IgM antibodies can easily be detected. Whereas, IgG antibodies are detected within one up two weeks of its infection, a peak concentration of this antibodies observed after four months, followed by decreasing to lower levels and remaining positive for the rest of the infected person lifespan. Having a positive IgG antibody test result with a negative IgM antibody shows as the patient have chronic T. gondii infection. Moreover, an individual having negative IgM antibody test basically excludes acute infection [8].

The prevalence rate of toxoplasmosis varies across different countries, in the world and even among different communities in the same region with in a country. In Ethiopia, the highest prevalence (95.1\%) rate of $T$. gondii was reported from Butajira among hospitalized patients found in the age group of 15-49 years [9].

Most of the time, psychiatric patients have a high risk of exposure to $T$. gondii infection due to lack of good personal hygiene, self-care skills, and a tendency to pica. Studies performed in various countries showed increased seroprevalence of toxoplasmosis in psychiatric patients [10]. However, no studies have been conducted in Ethiopia on the burden of toxoplasmosis among psychiatric patients. Therefore, the aim of this study was to determine the prevalence of $T$. gondii infection and associated risk factors among psychiatric patients.

\section{Methods}

\section{Study area, design and period}

An institution based cross-sectional study was conducted among psychiatric patients at the University of Gondar Comprehensive and Specialized Hospital, psychiatric outpatient's clinic, Gondar, Northwest Ethiopia. Gondar town is located $742 \mathrm{~km}$ away from Addis Ababa. Based on the 2007 Ethiopian census report, the population of Gondar town was estimated to be 323,900 [11]. Currently, the town has one referral hospital, University of Gondar Comprehensive and Specialized Hospital, which is a teaching as well as referral hospital. It serves for more than 5 million people. Psychiatric patients with the age of 18 and above and willing to participate in the study were included in the study but pregnant women and Human Immunodeficiency Virus (HIV) positive individuals were excluded. The study was carried out from February 1 to May 302018.

\section{Sample size determination and sampling technique}

The sample size was calculated by using Epi.info version 7.1.5.2 by taking a study conducted in Libiya with proportion for the control group $\mathrm{p} 1=33 \%$ and for case group p2 $=50.3 \%$ [12]. Therefore, the minimum required sample size was 276. By considering $10 \%$ non-response rate total sample size was 304 (152 for each group). A Systematic random sampling technique was used to select the study participants.

\section{Data collection procedure Questionnaire survey}

Data were collected by using pre-tested and semistructure Amharic version questionnaires. Psychiatric nurses were recruited for data collection and supervised by the principal investigator. The questionnaire had two parts, the first part consisted of socio-demographic characteristics of study participants which includes age, sex, marital status, residence, occupation. The second part of the questionnaire contained of potential risk factors.

\section{Sample collection and laboratory analysis}

Three milliliters of venous blood was collected by trained laboratory technologists and the samples were dispensed into serum sample test tube. One hundred fifty samples from the psychiatric outpatient clinic and one hundred fifty-two samples from VCT (Volunteer Counseling and Testing) clinic were transported to the hospital laboratory and screened for Toxoplasma gondii 
IgG/IgM antibodies. Urine was collected using a clean urine cup from all women study participants to screen pregnancy. Blood samples were centrifuged at $3000 \mathrm{rpm}$ for 5 min using centrifuge (Hettich, Germany) to separate serum portion of the blood component. The laboratory test analysis was done by the principal investigator.

\section{Toxoplasma gondii antibody test}

Anti-Toxoplasma gondii antibodies- IgG and IgM were determined by using on siteToxo IgG/IgM Rapid Test (CTK BIOTECH, San Diego, USA) which is a lateral flow chromatographic immunoassay for the simultaneous detection of IgG and IgM anti-Toxoplasma gondii antibodies in human serum or plasma.

\section{Urine HCG test}

For excluding pregnant women urine HCG (human chorionic gonadotropin) test was determined for both the cases and control group by using a rapid chromatographic immunoassay test strip (Assure Tech Co Ltd., Hangzhou) which detects the hormone HCG in a urine sample. This hormone is found only in the body during pregnancy.

\section{Human immune deficiency virus testing}

HIV screening test was carried out using first response, Uni-gold, and vikia HIV $1 / 2$ antibody screening test kit and following the manufacturer's instruction. The test kit is a visually qualitative immune assay for the detection of antibodies to HIV-1 and HIV-2 in whole blood, plasma or serum.

\section{Data quality control}

The questionnaire was prepared in English, translated to Amharic language. It was pre-tested on eight psychiatric patients and eight volunteers in other similar psychiatric and VCT clinics. One day training was given for data collectors. Manufacturer instructions were strictly followed throughout the laboratory procedures.

\section{Data processing and analysis}

Data were coded, entered, and cleaned using the statistical software Epi info version 7.1.5.2 and exported to the statistical package for social sciences (SPSS) version 20. Frequency tables, figures, and texts were used to present the summarized data. A Chi-square test was used to compare results and logistic regression analysis was conducted to check associations between dependent and independent variables. $P$ - value $<0.05$ was considered as statistically significant.

\section{Results}

General characteristics of study participants

A total of 304 participants who attended the University of Gondar Comprehensive and Specialized Hospital
Psychiatric and VCT clinic from February to May 2018 were included in the study. The subjects were categorized into psychiatric patients and non-psychiatric volunteers. The number of participants in each group was 152 . The mean age of the participants was $31 \pm 10.2$ years, with a minimum age of 18 and a maximum of 70 years. The proportion of males in the case and control groups were 55.9 and $61.2 \%$, respectively. The majority of the participants were Orthodox Christians, 258(84.9\%), lived in rural areas, $192(63.2 \%)$ and 108 (35.5\%) of them were government employees (Table 1).

Sero-prevalence of anti $T$. gondii antibodies among cases and control groups

The overall seroprevalence of $T$. gondii infection was 25 and $2.6 \%$ for IgG and IgM antibodies, respectively. The seroprevalence of anti- $T$. gondii IgG antibodies in psychiatric patients was $33.6 \%$ and it was significantly higher than that of the control group $16.4 \%(P=0.001)$. Two $(1.3 \%)$ of the psychiatric patients and $6(3.9 \%)$ of the control group were IgM positive. There was no statistically significant association in IgM seroprevalence between the psychiatric patients and the control group (Table 2).

\section{Risk factors associated with sero-prevalence of Toxoplasma gondii}

The multivariate logistic regression analysis showed that ownership of cats $(\mathrm{AOR}=2.862, \mathrm{CI}=1.445-5.666, P=$ $0.003)$, cleaning up of cat excretion $(\mathrm{AOR}=2.966, \mathrm{CI}=$ $1.317-2.652, P=0.007)$, and farming $(\mathrm{AOR}=2.058, \mathrm{CI}=$ $1.018-4.163 P=0.045)$ were significantly associated with the seroprevalence of anti- $T$. gondii IgG antibodies.

However, other characteristics such as sex, age group, residence, occupation, religion, a habit of eating uncooked meat and raw vegetables, hand washing habits, source of water, history of blood transfusion and habits of chat chewing did not show any significant association with anti-T. gondii IgG antibodies (Table 3).

\section{Sero-prevalence of toxoplasmosis among psychiatric patients with different clinical characteristics}

Out of the 152 psychiatric patients, almost half (49.3\%) were schizophrenic followed by severe depressive episodes $(29.6 \%)$, and bipolar disorder $(13.8 \%)$, whereas anxiety was the least (7.2\%).

In the cases group, the overall seroprevalence of anti T.gondii for both IgG and IgM antibodies was highest in schizophrenic patients. The overall sero-prevalence of anti-T.gondii among the different types of psychiatric patient's is shown on Fig. 1.

\section{Discussion}

Although several studies have been conducted on the seroprevalence of $T$. gondii infection in Ethiopia, most of 
Table 1 Socio demographic characteristics of the study subjects, Northwest Ethiopia, 2018

\begin{tabular}{|c|c|c|c|}
\hline Variables & $\begin{array}{l}\text { Psychiatric group } \\
\text { Frequency } \\
\mathrm{n}(\%)\end{array}$ & $\begin{array}{l}\text { Control group } \\
\text { Frequency } \\
\mathrm{n}(\%)\end{array}$ & $\begin{array}{l}\text { Total } \\
\text { Frequency } \\
\mathrm{n}(\%)\end{array}$ \\
\hline \multicolumn{4}{|l|}{ Sex } \\
\hline Male & $85(55.9)$ & $93(61.2)$ & $178(58.6)$ \\
\hline Female & $67(44.1)$ & $59(38.8)$ & $126(41.4)$ \\
\hline \multicolumn{4}{|l|}{ Age } \\
\hline $\begin{array}{l}\leq 20 \\
21-40\end{array}$ & $\begin{array}{l}15(9.9) \\
98(64.5)\end{array}$ & $\begin{array}{l}3(2.0) \\
136(89.5)\end{array}$ & $\begin{array}{l}18(5.9) \\
234(77.0)\end{array}$ \\
\hline$\geq 41$ & $39(25.7)$ & $13(8.6)$ & $52(17.1)$ \\
\hline \multicolumn{4}{|l|}{ Resident } \\
\hline Urban & $75(49.3)$ & $37(24.3)$ & $112(36.8)$ \\
\hline Rural & $77(50.7)$ & $115(75.7)$ & $192(63.2)$ \\
\hline \multicolumn{4}{|l|}{ Occupation } \\
\hline Student & $29(19.1)$ & $35(23.0)$ & $64(21.1)$ \\
\hline Government & $29(19.1)$ & 79 (52.0) & $108(35.5)$ \\
\hline Daily labor & $20(13.2)$ & $11(7.2)$ & $31(10.2)$ \\
\hline Farmer & $55(36.2)$ & $18(11.8)$ & $73(24.0)$ \\
\hline Merchant & $9(5.9)$ & $9(5.9)$ & $18(5.9)$ \\
\hline \multicolumn{4}{|l|}{ Religion } \\
\hline Orthodox & $135(88.8)$ & $123(80.9)$ & $258(84.9)$ \\
\hline Protestant & $3(2.2)$ & $11(7.2)$ & $14(4.6)$ \\
\hline Muslim & $12(7.9)$ & $17(11.2)$ & $29(9.5)$ \\
\hline Other & $2(1.3)$ & $1(0.7)$ & $3(1.0)$ \\
\hline \multicolumn{4}{|c|}{ Level of education } \\
\hline Illiterate & $55(36.2)$ & $10(6.6)$ & $65(21.4)$ \\
\hline Elementary & $36(23.7)$ & $15(9.9)$ & $51(16.8)$ \\
\hline Secondary & $25(16.4)$ & $19(12.5)$ & $44(14.5)$ \\
\hline Certificate & $36(23.7)$ & $108(71.1)$ & $144(47.4)$ \\
\hline
\end{tabular}

the previous studies focused on pregnant women and immunocompromised patients. Based on our review of literature no evidence of other investigations found related to the current study in Ethiopia; so that the present study was conducted in order to compare the prevalence of $T$. gondii infection between patients with psychiatric disorder and controls, as well as to evaluate the potential association between $T$. gondii infection and associated

Table 2 Sero-prevalence of T. gondii among psychiatric patients and control group, Northwest Ethiopia, 2018

\begin{tabular}{lllll}
\hline Variables & $\begin{array}{l}\text { Cases (psychiatric patients) } \\
\mathrm{n}(\%)\end{array}$ & $\begin{array}{l}\text { Control } \\
\mathrm{n}(\%)\end{array}$ & $X^{2}$ & $P$. value \\
\hline IgG positive & $51(33.6 \%)$ & $25(16.4 \%)$ & 11.860 & $0.001^{*}$ \\
IgG negative & $101(66.4 \%)$ & $127(83.6 \%)$ & & \\
IgM positive & $2(1.3 \%)$ & $6(3.9 \%)$ & 2.054 & 0.143 \\
IgM negative & $150(98.7 \%)$ & $146(96.1 \%)$ & & \\
\hline
\end{tabular}

*statistically significant at $P$. Value $<0.005$ risk factors in University of Gondar Comprehensive and Specialized Hospital Psychiatric clinic outpatients.

A number of investigations showed that chronic Toxoplasma infection may alter human behavior and causes psychiatric disorders. These behavioral changes related to infection with $T$. gondii may be due to the parasite itself, which causes infection with nerve damage. The cytokine IFN- $\gamma$, is mainly responsible for immunological defense against $T$. gondii is essential in all infected tissues, including the central nervous system [13-15].

Moreover, as $T$. gondii $\mathrm{s}$ is a neurotropic organism with a complex mechanism of access to the brain where it encysts in glial cells, neurons, and astrocytes. Damage is characterized by many foci of enlarging necrosis and microglial nodules. It might also incorporate its genome into the cellular Deoxyribonucleic acid with the potential of altering brain function or modifying the growing neuronal cell in vitro [16].

The overall seroprevalence of $T$. gondii infection in this study was $27.6 \%$. The finding is in line with those of previous similar studies carried out in Nigeria (32.1\%) [17] and Ahvat, Iran (28.3\%) [18]. However, it is lower than those studies done in Libya (41.7\%) [12], Western Romania (57.7\%) [19] \{and Mashhad, Northwest Iran (43.2\%) [20]\}. On the other hand, the seroprevalence of T. gondii antibodies in the present study was higher than studies conducted in Durango city, Northern Mexico (12.5\%) [21], India (20.3\%) [22] and Mexico (6.1\%) [3]. The most possible explanation for such differences in seroprevalence of $T$. gondii infection might be due to differences in culture, socioeconomic status, populations sampled, climatic condition, literacy status of the study participants, personal hygiene, types of the laboratory method used and environmental exposure.

This study showed that the seroprevalence rate for antiT. gondii IgG antibodies in psychiatric patients $51(33.6 \%)$ were statistically higher than that in the control group. According to this result, chronic T. gondii infection in psychiatric patients $51(33.6 \%)$ was higher than in the control group which was found to be 25 (16.4\%). This finding was supported by a seroprevalence study conducted in Nigeria (30.7\%) IgG antibody in mental disabled patients than the $17.8 \%$ in the control group [17]. A study in Tripoli, Libya also found a high (50.3\%) seroprevalence rate of IgG antibodies in psychiatric patients than for the 33\% in the control volunteers (33\%) [12]. The difference in seroprevalence of anti-T. gondii IgG between psychiatric patients and controls could be due to the difference in sanitation practices. In addition, most psychiatric patients were from the lower socio-economic level. On the other hand, the seroprevalence of anti- $T$. gondii IgM antibodies in psychiatric patients $1.3 \%$ was lower than $3.9 \%$ in the control group, even though the difference was not statistically significant ( $p$ value $=0.143$ ). Similar findings were reported from Nigeria 
Table 3 Bivariate and multivariate logistic regression analysis on sero-prevalence of T. gondii among study participants Northwest Ethiopia, 2018

\begin{tabular}{|c|c|c|c|c|c|}
\hline \multirow[t]{2}{*}{ Variables } & \multicolumn{2}{|c|}{ Presence of IgG } & \multirow[t]{2}{*}{$\operatorname{COR}(95 \% \mathrm{Cl})$} & \multirow[t]{2}{*}{$\mathrm{AOR}(95 \% \mathrm{Cl})$} & \multirow[t]{2}{*}{$P$ value } \\
\hline & Yes & No & & & \\
\hline \multicolumn{6}{|l|}{ Sex } \\
\hline Male & $42(23.6 \%)$ & $136(76.4 \%)$ & $0.836(.495-1.411)$ & & \\
\hline Female & $34(27.0 \%)$ & $92(73.0 \%)$ & 1 & & \\
\hline \multicolumn{6}{|l|}{ Age } \\
\hline$\leq 20$ & 7 (38.9\%) & $11(61.1 \%)$ & $2.071(.766-5.600)$ & & \\
\hline $21-40$ & $55(23.5 \%)$ & 179 (76.5\%) & 1.727(.559-5.339) & & \\
\hline$\geq 41$ & $14(26.9 \%)$ & $38(73.1 \%)$ & 1 & & \\
\hline \multicolumn{6}{|l|}{ Resident } \\
\hline Urban & $33(29.5 \%)$ & 79 (70.5\%) & $1.447(.853-2.457)$ & $0.697(.334-1.455)$ & 0.337 \\
\hline Rural & $43(22.4 \%)$ & 149 (77.6\%) & 1 & 1 & \\
\hline \multicolumn{6}{|l|}{ Occupation } \\
\hline Student & $20(31.2 \%)$ & $44(68.8 \%)$ & $2.000(.976-4.099)$ & & \\
\hline Government & $20(18.5 \%)$ & 88 (81.5\%) & $0.955(.380-2.395)$ & & \\
\hline Daily labor & $10(32.2 \%)$ & $21(67.7 \%)$ & 1.054(.509-2.181) & & \\
\hline Farmer & $22(30.1 \%)$ & $51(69.9 \%)$ & 7.727(.961-62.156) & & \\
\hline Merchant & $1(5.6 \%)$ & $17(94.4 \%)$ & $1.061(.248-4.531)$ & & \\
\hline Other & $3(30 \%)$ & $7(70 \%)$ & 1 & & \\
\hline Level of education & $21(32.3 \%)$ & $44(67.7 \%)$ & $1.145(.517-2.538)$ & & \\
\hline Illiterate & 15 (29.4\%) & $36(70.6 \%)$ & $1.273(.548-2.957)$ & & \\
\hline Elementary & $12(27.3 \%)$ & $32(72.7 \%)$ & $1.977(1.018-3.840)$ & & \\
\hline Secondary & $28(19.4 \%)$ & $116(80.6 \%)$ & 1 & & \\
\hline \multicolumn{6}{|l|}{ Certificate } \\
\hline \multicolumn{6}{|l|}{ Cat owner } \\
\hline Yes & $56(39.4 \%)$ & $86(60.6 \%)$ & $4.623(2.598-8.229)$ & $2.862(1.445-5.666)$ & $0.003^{*}$ \\
\hline No & $20(12.3 \%)$ & $142(87.7 \%)$ & 1 & 1 & \\
\hline \multicolumn{6}{|c|}{ Clean up cat excretion } \\
\hline Yes & $33(55.9 \%)$ & $26(44.1 \%)$ & $5.962(3.239-10.977)$ & $2.966(1.317-2.652)$ & $0.007^{*}$ \\
\hline No & $43(17.6 \%)$ & $202(82.4 \%)$ & 1 & & \\
\hline \multicolumn{6}{|c|}{ Raw meat consumption } \\
\hline Yes & $36(30.5 \%)$ & $82(69.5 \%)$ & $1.602(.948-2.710)$ & $1.445(.787-2.652)$ & 0.235 \\
\hline No & $40(21.5 \%)$ & $146(78.5 \%)$ & 1 & 1 & \\
\hline \multicolumn{6}{|c|}{ Raw vegetable consumption } \\
\hline Yes & $39(23.5 \%)$ & $127(76.5 \%)$ & $0.838(.498-1.410)$ & & \\
\hline No & $37(26.8 \%)$ & $101(73.2 \%)$ & 1 & & \\
\hline \multicolumn{6}{|l|}{ Farming } \\
\hline Yes & $43(34.7 \%)$ & $81(65.3 \%)$ & $2.365(1.394-4.012)$ & $2.058(1.018-4.163)$ & $0.045^{*}$ \\
\hline No & $33(18.3 \%)$ & $147(81.7 \%)$ & 1 & 1 & \\
\hline \multicolumn{6}{|c|}{ History of blood transfusion } \\
\hline Yes & $9(31.0 \%)$ & $20(69.0 \%)$ & $1.397(.607-3.215)$ & & \\
\hline No & $67(24.4 \%)$ & $208(75.6 \%)$ & 1 & & \\
\hline \multicolumn{6}{|c|}{ Habit of chat chewing } \\
\hline Yes & $14(29.8 \%)$ & $33(70.2 \%)$ & $1.334(1.671-2.653)$ & & \\
\hline
\end{tabular}


Table 3 Bivariate and multivariate logistic regression analysis on sero-prevalence of T. gondii among study participants Northwest Ethiopia, 2018 (Continued)

\begin{tabular}{|c|c|c|c|c|c|}
\hline \multirow[t]{2}{*}{ Variables } & \multicolumn{2}{|c|}{ Presence of $\lg G$} & \multirow[t]{2}{*}{$\operatorname{COR}(95 \% \mathrm{Cl})$} & \multirow[t]{2}{*}{ AOR(95\% Cl) } & \multirow[t]{2}{*}{$P$ value } \\
\hline & Yes & No & & & \\
\hline No & 62 (24.1\%) & 195 (75.9\%) & 1 & & \\
\hline
\end{tabular}

COR Crude odds ratio, AOR adjusted odds ratio, $C l$ Confidence interval, * statistically significant at $P<0.05{ }^{* *}$ statistically significant at $P<0.01$

[17] and Iran [5]. The possible reason for the high seroprevalence of anti-T. gondii IgM antibody in the control group compared with the cases may be due to the living of control group in areas that frequently expose people to infections.

In the current study, individuals who had cats $(\mathrm{AOR}=$ $2.862, \mathrm{CI}=1.445-5.666, p=0.003$ ) showed a statistically significant association in the seroprevalence of anti-T. gondii IgG antibodies. This finding was supported by those of studies conducted in Libya [12], Central Ethiopia [23], and Nazareth town [24]. This is mainly due to the fact that cats are a definitive host for T. gondii, and play an important role in the transmission and continuing this parasite in nature [25].

In addition, individuals who frequently cleaned cat excretions showed a statistically significant association with the seroprevalence of anti- $T$. gondii IgG antibodies. The finding was similar to that of a study conducted in Malaysia [26]. One of the causes for this high prevalence could be attributed to the close contact of humans with cats as they excrete millions of oocysts within a short period of time and play a major role in the transmission of T. gondii [24]. In our culture cats and dogs have a close proximity to people. Cats are definitive hosts where the sexual multiplication of $T$. gondii takes place [27].

Farming (gardening and agriculture) $(\mathrm{AOR}=2.058, \mathrm{CI}=$ $1.018-4.163, P=0.045$ ) was significantly associated with the seroprevalence of anti- $T$. gondii IgG antibody. This is in agreement with a study in Gondar [28] and Bench Maji zone [29]. This might have showed that contact with soil could be potential risk factor for an increasing seroprevalence of anti-T. gondii IgG antibodies. This may be due to the fact of that the oocyst of $T$. gondii can remain infective for 12 to 24 months under favorable conditions [30]. In the present study, age and sex didn't show any statistically significant association with the seroprevalence of $T$. gondii IgG antibody. On the other hand, a study conducted in Mashhad city (Iran), age and sex showed a statistically significant association with the seroprevalence of anti-T. gondii IgG antibody in which females and study participants above the age of 40 years were at risk of infection [31]. This variation might be due to differences in type of study population, and study period.

In the present study a high seroprevalence of anti- $T$. gondii IgG antibody was observed among schizophrenic patients (45.3\%). This is in-line with a finding reported from Turkey (43.5\%) [32]. However, it is higher than the finding of studies conducted in Iran (18.5\%) [20], Malaysia (30.7\%) [26], and Mexico (26.3\%) [21]. It was lower than the result noted in Turkey (66\%) [33], Libya (53.4\%) [12], and Yemen (53\%) [34]. Being high seroprevalence of anti-T. gondii antibody among schizophrenic patients may be due to the hypothesis that $T$. gondii is potentially a relevant infection in some cases of schizophrenia $[35,36]$ or may be related to the fact that patients with schizophrenia have inadequate hygiene and selfcare skills, and have a greater tendency to eat contaminated or dirty particles [37].

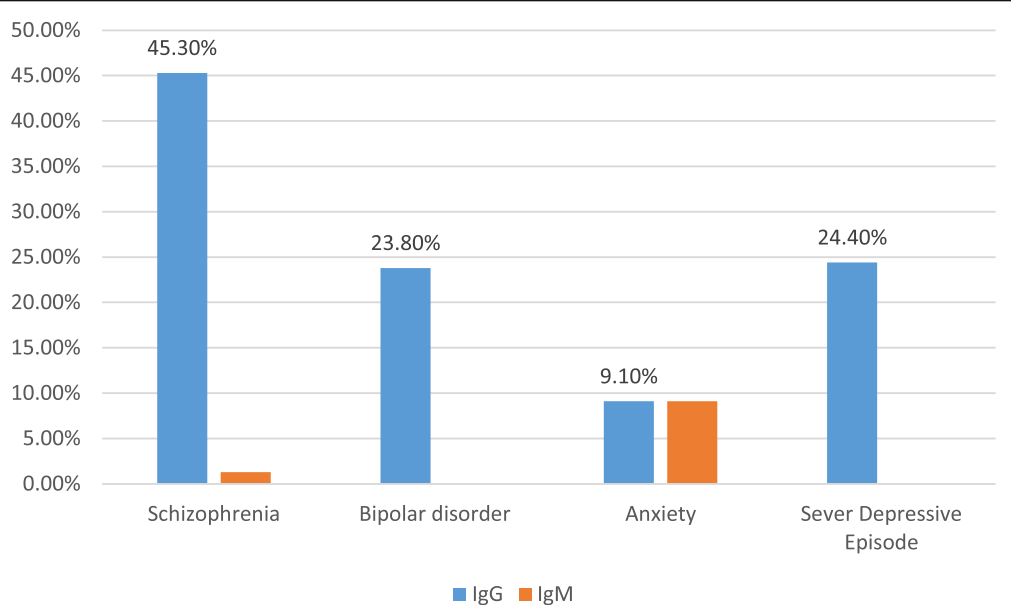

Fig. 1 Sero-prevalence for T. gondii antibodies in psychiatric patients at University of Gondar psychiatric clinic, Northwest Ethiopia, February to May 2018 


\section{Conclusions}

In the present study, the seroprevalence of $T$. gondii infection among the psychiatric outpatients was significantly higher than the control group. Cat and dog ownership, cleaning up of cat excretion, and farming (agriculture and gardening) might be the most important routes of transmission in our study subjects. The study also found that the prevalence of $T$. gondii infection was higher in schizophrenic patients compared to the other types of psychiatric patients. Thus, we recommend that clinicians should consider screening of psychiatric patients for $T$. gindii.

\section{Abbreviations \\ AIDS: Acquired Immune Deficiency Syndrome; CNS: Central Nervous System; ELISA: Enzyme Linked ImmunoSorbent Assay; HIV: Human Immunodeficiency Virus; IFAT: Immuno Fluorescence Assay Test; IgA: Immunoglobulin A; IgE: Immuno globulin E; IgG: Immuno globulin G; IgM: Immuno globulin M; LAT: Latex Agglutination Test; PCR: Polymerase Chain Reaction; VCT: Voluntary Counselling and Testing}

\section{Acknowledgments}

We acknowledge the study participants, parents of psychiatric patients and nurses in the Psychiatric and voluntary and counseling testing clinic of the University of Gondar Comprehensive and Specialized Hospital.

\section{Authors' contributions}

$B A, Y T$, and HT analyzed the data, drafted the manuscript. While AJZ, LW, AA, and NY involved in data analysis and critically reviewed the manuscript. All authors approved the manuscript.

\section{Funding}

Financial support was provided by the University of Gondar. However, the institution has no role in the design of the study, collection, analysis, and interpretation of the data and in writing the manuscript.

\section{Availability of data and materials}

I confirmed that all the data for this manuscript are available, if someone wants to request the data can contact Yalewayker Tegegne.

\section{Ethics approval and consent to participate}

The study was approved by the School of Biomedical and Laboratory Science Research and Ethical Review Committee (reference no. SBMLS/870/ 10). A permission letter was also obtained from the clinical director of the hospital and head of the Psychiatric clinic. Informed written consent was obtained from the study participants and following explanation of the purpose, potential risk and discomfort and justification of the study consent was also obtained from parents and guardians of the study participants under 16 years old. All information obtained from the participants was coded to maintain confidentiality. Laboratory test results were communicated to responsible clinicians, and participants positive for $T$. gondii antibodies were communicated on the phone and linked to their respected clinicians in the hospital.

\section{Consent for publication}

$$
\text { Not applicable. }
$$

\section{Competing interests}

The authors declare that they have no competing interests.

\section{Author details}

${ }^{1}$ Universit of Gondar Hospital, College of Medicine and Health Sciences, University of Gondar, Gondar, Ethiopia. '2Department of Medical Parasitology, School of Biomedical and Laboratory Sciences, College of Medicine and Health Sciences, University of Gondar, Gondar, Ethiopia. ${ }^{3}$ Department of Psychiatric Nursing, Department of Psychiatry, School of Medicine, College of Medicine and Health Sciences University of Gondar, Gondar, Ethiopia.
Received: 29 September 2018 Accepted: 30 June 2019

Published online: 04 July 2019

\section{References}

1. Goldstein EJ, Montoya JG, Remington JS. Management of Toxoplasma gondii infection during pregnancy. Clin Infect Dis. 2008;47(4):554-66.

2. Abu-Madi MA, Al-Molawi N, Behnke JM. Seroprevalence and epidemiological correlates of toxoplasma gondii infections among patients referred for hospital-based serological testing in Doha, Qatar. Parasit Vectors. 2008;1(1):39.

3. Alvarado-Esquivel C, Mercado-Suarez MF, Rodríguez-Briones A, Fallad-Torres L, Ayala-Ayala JO, Nevarez-Piedra LJ, et al. Seroepidemiology of infection with toxoplasma gondii in healthy blood donors of Durango, Mexico. BMC Infect Dis. 2007;7(1):75

4. $\quad$ Flegr J. How and why toxoplasma makes us crazy. Trends Parasitol. 2013; 29(4):156-63.

5. Hamidinejat H, Ghorbanpoor M, Hosseini H, Alavi SM, Nabavi L, Jalali MHR, et al. Toxoplasma gondii infection in first-episode and inpatient individuals with schizophrenia. Int J Infect Dis. 2010;14(11):e978-e81.

6. Luft BJ, Hafner R, Korzun AH, Leport C, Antoniskis D, Bosler EM, et al. Toxoplasmic encephalitis in patients with the acquired immunodeficiency syndrome. N Engl J Med. 1993;329(14):995-1000.

7. Torgerson PR, Mastroiacovo P. The global burden of congenital toxoplasmosis: a systematic review. Bull World Health Organ. 2013:91:501-8.

8. Montoya J, Liesenfeld O. Toxoplasmosis. Lancet. 2004;363:1965-76. https:// doi.org/10.1016/S0140-6736(04).

9. Jilo K, Adem J. Toxoplasmosis and its Current Status in Ethiopia: A Review; 2016.

10. Zhu S. Psychosis may be associated with toxoplasmosis. Med Hypotheses. 2009;73(5):799-801.

11. CAC. Summery and statistical report of the 2007 population and housing census Addis abeba. Population and housing census commission; 2008. p. 57-60.

12. Elsaid MMA, Azbedah AG, Dia Eddin E, EL-Alem and Alkout A. The prevalence of Toxoplasma gondii infection in psychiatric patients in Tripoli, Libya. J Am Sci 2014;10(5):135-40]. (ISSN: 1545-1003).

13. Henriquez S, Brett R, Alexander J, Pratt J, Roberts C. Neuropsychiatric disease and toxoplasma gondii infection. Neuroimmunomodulation. 2009;16(2):122-33.

14. Tamer GS, Dundar D, Yalug I, Caliskan S, Yazar S, Aker A. The schizophrenia and toxoplasma gondii connection: infectious, immune or both? Adv Ther. 2008;25(7):703.

15. Rozenfeld C, Martinez R, Seabra S, Sant'Anna C, Gonçalves JGR, Bozza M, et al. Toxoplasma gondii prevents neuron degeneration by interferon- $\gamma$ activated microglia in a mechanism involving inhibition of inducible nitric oxide synthase and transforming growth factor- $\beta 1$ production by infected microglia. Am J Pathol. 2005;167(4):1021-31.

16. Fekadu A, Shibre T, Cleare AJ. Toxoplasmosis as a cause for behaviour disorders-oveniew of evidence and mechanisms. Folia Parasitol. 2010;57(2):105

17. James BO, Agbonile IO, Okolo M, Lawani AO, Omoaregba JO. Prevalence of toxoplasma gondii infection among individuals with severe mental illness in Nigeria: a case control study. Pathog Glob health. 2013;107(4):189-93.

18. Khademvatan S, Khajeddin N, Izadi S, Saki J. Study of toxoplasma Gondii infection in patients with bipolar disorder. J Med Sci (Faisalabad). 2013;13(3): 215-20

19. Olariu T, Capraru I, Papava I, Romosan R, Dehelean L, Lupu M. Seroprevalence of toxoplasma gondii in Romanian psychiatric patients. Eur Psychiatry. 2017:41:S825.

20. Abdollahian E, Shafiei R, Mokhber N, Kalantar K, Fata A. Seroepidemiological study of toxoplasma gondii infection among psychiatric patients in Mashhad, northeast of Iran. Iran J Parasitol. 2017;12(1):117.

21. Alvarado-Esquivel C, Alanis-Quiñones O-P, Arreola-Valenzuela M-Á Rodríguez-Briones A, Piedra-Nevarez L-J, Duran-Morales E, et al. Seroepidemiology of toxoplasma gondii infection in psychiatric inpatients in a northern Mexican city. BMC Infect Dis. 2006;6(1):178.

22. Sundar P, Mahadevan A, Jayshree R, Subbakrishna D, Shankar S. Toxoplasma seroprevalence in healthy voluntary blood donors from urban Karnataka. Indian J Med Res. 2007;126(1):50.

23. Gebremedhin EZ, Abebe AH, Tessema TS, Tullu KD, Medhin G, Vitale M, et al. Seroepidemiology of toxoplasma gondii infection in women of childbearing age in Central Ethiopia. BMC Infect Dis. 2013;13(1):101.

24. Negash T, Tilahun G, Medhin G. Seroprevalence of toxoplasma gondii in Nazareth town, Ethiopia. East Afr J Public Health. 2008;5(3):211-4. 
25. Dabritz H, Conrad PA. Cats and toxoplasma: implications for public health. Zoonoses Public Health. 2010;57(1):34-52.

26. Juanah LY, Jalaludin J, Osman M, Osman ZJ. Seroprevalence of toxoplasma gondii among schizophrenics at hospital Kajang. Am J Infect Dis. 2013;9(1):11.

27. Dubey J, Jones J. Toxoplasma gondii infection in humans and animals in the United States. Int J Parasitol. 2008;38(11):1257-78.

28. Muluye D, Wondimeneh Y, Belyhun Y, Moges F, Endris M, Ferede G, et al. Prevalence of toxoplasma gondii and associated risk factors among people living with HIV at Gondar University hospital, Northwest Ethiopia. ISRN Trop Med. 2013;2013.

29. Abamecha F, Awel H. Seroprevalence and risk factors of toxoplasma gondii infection in pregnant women following antenatal care at Mizan Aman general hospital, bench Maji zone (BMZ), Ethiopia. BMC Infect Dis. 2016;16(1):460.

30. Dubey J. Sources of toxoplasma gondii infection in pregnancy: until rates of congenital toxoplasmosis fall, control measures are essential. BMJ. 2000; 321(7254):127.

31. Maryam Gholami M, Farahnaz Tehranian M, Ali Hasani M. Seroprevalence of anti-toxoplasma Gondii antibodies in healthy voluntary blood Donors from Mashhad City, Iran. Arch Iran Med. 2017;20(7):441.

32. Karabulut N, Bilgiç S, Gürok MG, Karaboga F. Is there any role of latent toxoplasmosis in schizophrenia disease? J Chin Med Assoc. 2015;78:533e7.

33. Cetinkaya Z, Yazar S, Gecici O, Namli MN. Anti-toxoplasma gondii antibodies in patients with schizophrenia-preliminary findings in a Turkish sample. Schizophr Bull. 2007:33(3):789-91.

34. Mahmoud SS, Hasan MS. Seroprevalence of toxoplasmosis among schizophrenic patients. Yemeni J Med Sci. 2009:3:7.

35. Torrey EF, Bartko JJ, Yolken RH. Toxoplasma gondii and other risk factors for schizophrenia: an update. Schizophr Bull. 2012;38(3):642-7.

36. Torrey EF, Yolken RH. Toxoplasma gondii and schizophrenia. Emerg Infect Dis. 2003;9(11):1375.

37. El-Sayed NM, Ismail KA. Relationship between Toxocara canis infection and schizophrenia. Rawal Med J. 2012;37(02):155-61.

\section{Publisher's Note}

Springer Nature remains neutral with regard to jurisdictional claims in published maps and institutional affiliations.

Ready to submit your research? Choose BMC and benefit from:

- fast, convenient online submission

- thorough peer review by experienced researchers in your field

- rapid publication on acceptance

- support for research data, including large and complex data types

- gold Open Access which fosters wider collaboration and increased citations

- maximum visibility for your research: over $100 \mathrm{M}$ website views per year

At $\mathrm{BMC}$, research is always in progress.

Learn more biomedcentral.com/submissions 